\title{
NEUROFIBROMATOSIS WITH PATHOLOGICAL FRACTURES IN THE NEWBORN
}

\author{
BY \\ FLORENCE McKEOWN and MURIEL J. L. FRAZER \\ From the Department of Pathology, Queen's University, and City Hospital, Belfast
}

(RECEIVED FOR PUBLICATION JULY 29, 1960)

Neurofibromatosis may be recognized in childhood, though it is unusual for the full syndrome to be present at an early age. Thus skin pigmentation may be the only manifestation in infancy, later to be followed by the development of skin tumours, skeletal and other abnormalities.

The following case of neurofibromatosis is of interest in that it occurred in a newborn infant who presented with skin pigmentation, bowing of the legs, pathological fractures, cardiac irregularity, and enlargement of the clitoris.

\section{Case Report}

Barbara, the second child of young, unrelated parents, whose other child is healthy, was admitted to the Neonatal Sick Unit of the Jubilee Maternity Hospital, Belfast, on October 27, 1959, being then 11 days old. She was referred because of 'a patch of skin which goes white when she cries' (and she cried a great deal), but it was found that while there was indeed an irregular area over the right clavicle which did not flush with the rest of the skin, there were also café au lait blotches on the trunk, a patch of alopecia in the right parietal region, enlargement of the clitoris, bowing and thickening of the left leg, and reluctance to move the right arm.

Radiographs showed fractures of the left tibia and fibula and right ulna and an unusual bowing of the right tibia and fibula. The femora appeared normal. The appearances were not considered typical of Albright's disease (Figs. 1 and 2).

On October 28, the baby had a sudden, severe, cyanotic attack, with an irregular apex rate of 240 per minute. E.C.G. showed 'runs of atrial tachycardia and multiple ectopics, mainly ventricular'. The tachycardia ceased after the administration of intravenous digoxin and no further attacks were observed. The baby, however, failed to thrive.

No abnormality was found in the blood chemistry, apart from a moderately raised blood urea $(84 \mathrm{mg}$. \%). A few pus cells were present in a catheter sample and there was a moderate growth of coliform bacilli sensitive to streptomycin only, a course of which was given, and by November 10 the urine was clear and sterile. Despite this, however, and though no other clinical sign of infection was apparent, the temperature began to rise, and in spite of further antibiotic treatment, she died on November 23, by which time the brownish pigmentation involved almost half the surface of the trunk.

The genital abnormality was not, unfortunately, investigated fully during life; on rectal examination a normal-seeming infantile uterus was found, but in view of the multiple fractures, and, indeed, of her steady downhill course, it was not possible to collect a 24-hour specimen of urine for endocrine assay.

Post-mortem Examination. At autopsy the main external features of note were the bowing of the tibiae with fractures palpable in the lower third of the left tibia, and in the right ulna, the café au lait spots around the umbilicus, slight alopecia in the right parietal region, and enlargement of the clitoris. There were no skin tumours.

Macroscopically the heart and lungs showed no abnormality. The abdominal organs were quite normal and the only positive finding in the abdomen was the presence of a $1 \mathrm{~cm}$. nodule of tissue related to the coeliac plexus. The cranial contents appeared normal. The tibiae and fibulae and samples of other bones were removed for histology. All organs were examined histologically, but only the relevant sections will be described.

\section{Histology}

Left tibia. In general the periosteum showed slight thickening, and the nerves related to it showed a diffuse intraneural fibrosis. There was slight osteoclastic proliferation in the underlying cortex, but on the whole the cortex was thicker than normal and the trabeculae were broad and well formed. At the site of the fracture there was much proliferation of granulation tissue and a little calcifying cartilage, but the broken ends of the bone were largely separated by a mass of neurofibromatous tissue developing in the medullary cavity, and situated along the course of a main nerve trunk which could be seen perforating the adjacent cortex. The interlacing bundles of fibrous tissue intimately mixed with nerve fibres, with more obvious Schwann cell proliferations forming Verocay bodies, identified the lesion as a neurofibroma (Fig. 3). A feature of the tumour was the presence of many large thin-walled blood vessels coursing within the affected nerves (Fig. 4). Other neurofibromatous nodules were present in the medullary cavity even 


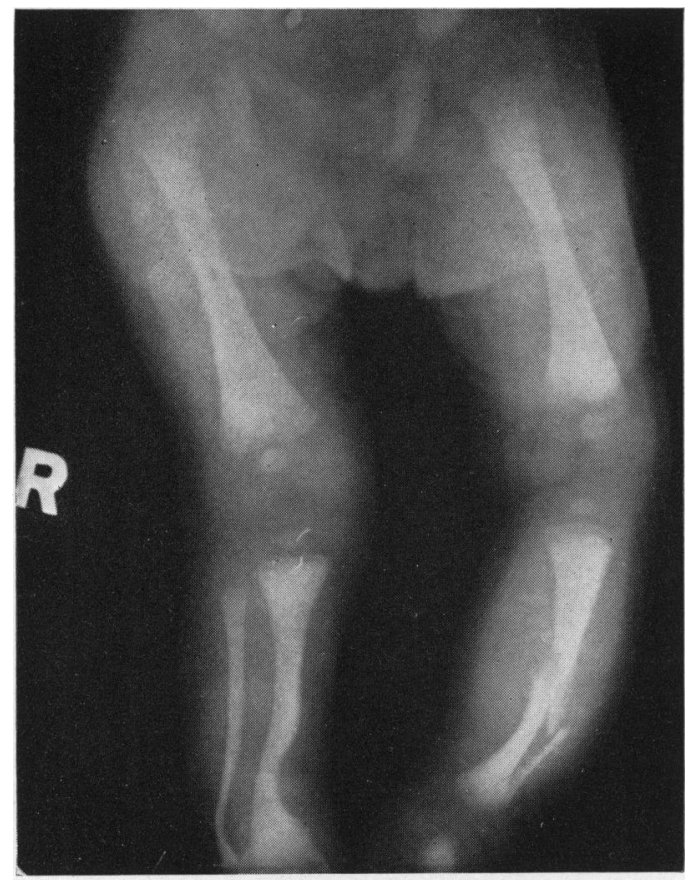

FIG. 1.

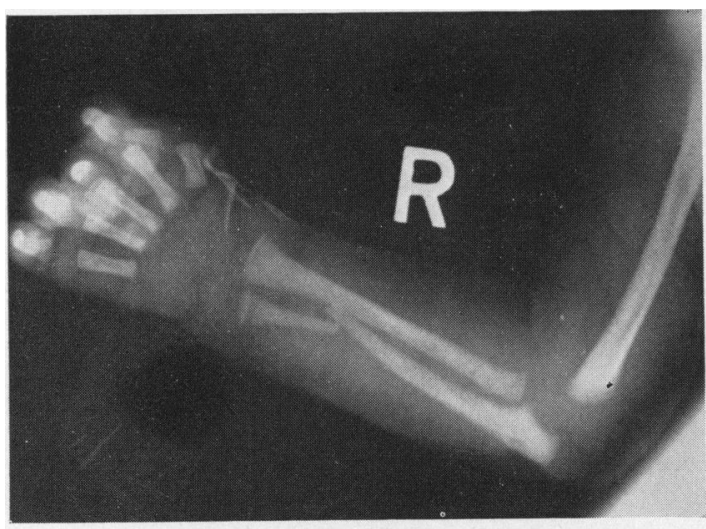

FIG. 2.

FIG. 1.-Radiograph of lower limbs showing bowing of right tibia and fibula, and fractures of left tibia and fibula.

FIG. 2.-Radiograph showing fracture of distal third of right ulna. FIG. 3.-Section of left tibia showing intramedullary neurofibroma at level of fracture. (H. and E. $\times 35$.)

FIg. 4.-Section of left tibia, showing the rich vascular pattern in a large intramedullary neurofibroma. (H. and E. $\times 85$.)

at a distance from the fracture and showed the same rich vascularity.

In the right tibia, where bowing was the only macroscopic change, histological examination revealed neurofibromatosis of the periosteal and intramedullary nerves, but not to such a degree as in the fractured tibia. There was also some thickening of the cortex, with fibrosis of

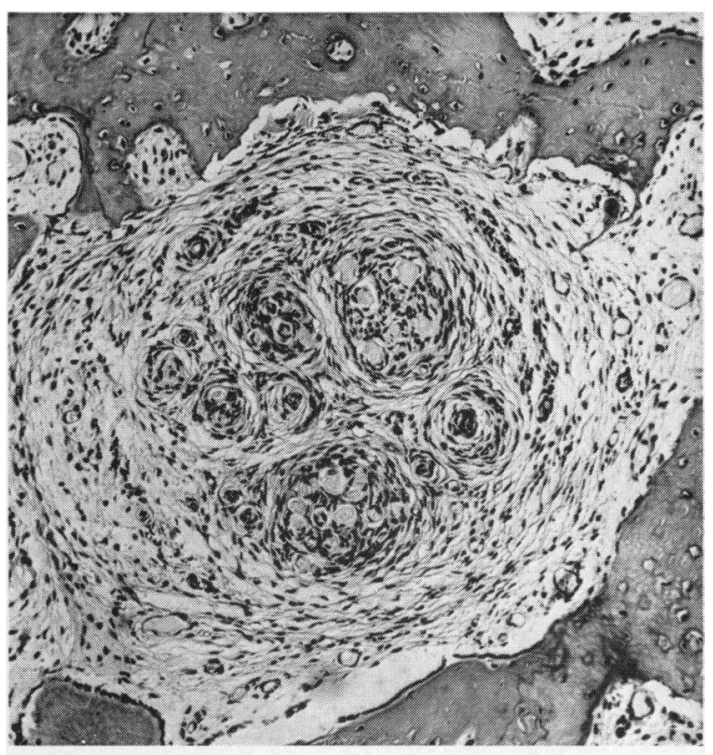

FIG. 3.

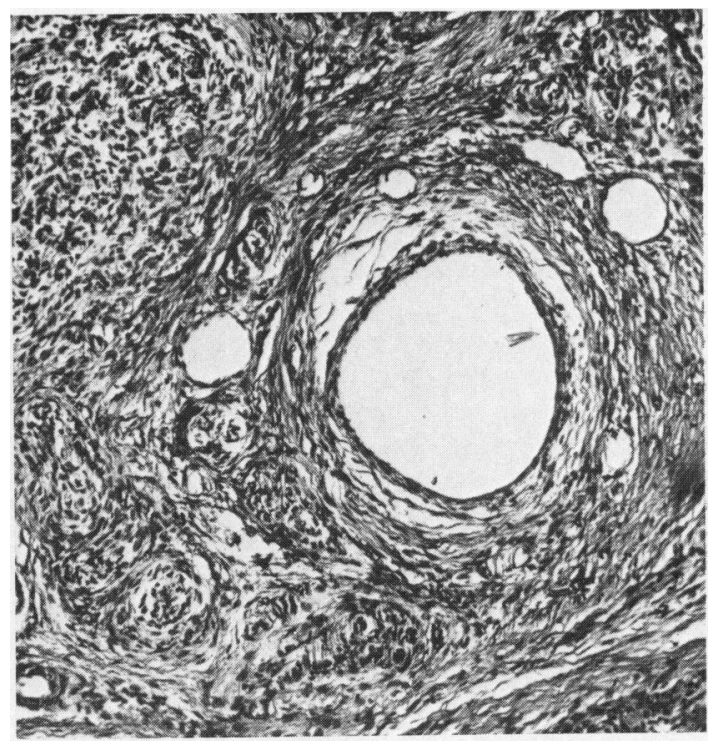

FIG. 4.

the marrow. Skull, pelvic bones, ribs and vertebrae showed no abnormality histologically.

Nodule from coeliac plexus. This proved to be a neurofibroma in which there was some mucoid degeneration of the fibrous tissue. There were some ganglion cells present also.

Vagi. These were examined at several levels and 
throughout their intrathoracic course the nerves showed much intraneural fibrosis resulting in expansion of the trunks to about twice their normal size. There was some loss of nerve fibres, but the perineural sheath, though thickened, was not disrupted (Fig. 5). Other peripheral nerves, both visceral and skeletal, showed diffuse thickenings and clubbed expansions which were only detected on histological examination. No cause for the enlarged clitoris could be found. All endocrine organs appeared normal (though with minor abnormalities of innervation) and no lesion could be detected in the hypothalamus.

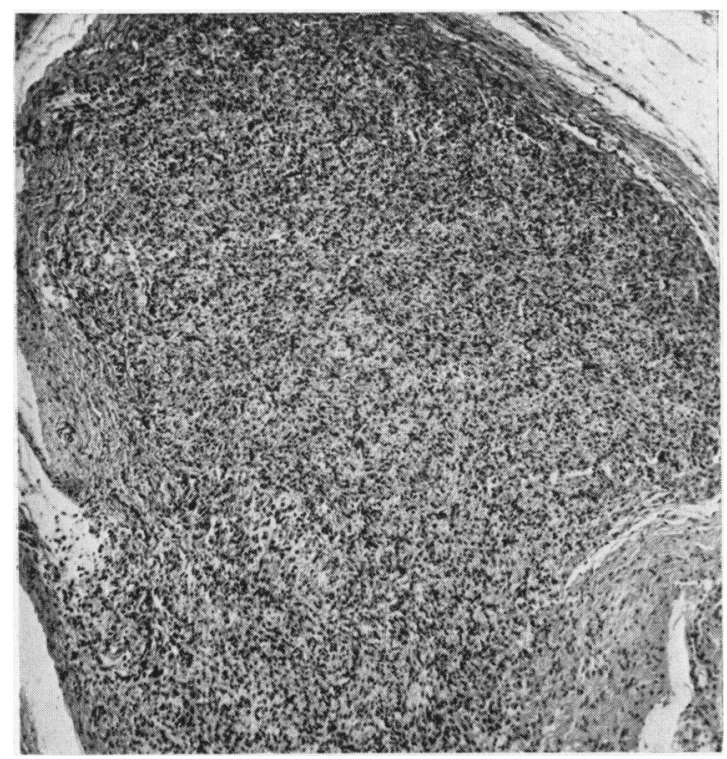

Fig. 5.-Vagus, showing neurofibromatous expansion of the nerve, and slight perineural fibrosis. (H. and E. $\times 35$.)

\section{Discussion}

Skeletal changes in neurofibromatosis have been recognized for a considerable time and have been well documented (Brooks and Lehman, 1924; Holt and Wright, 1948; Levene, 1959). They have been reportcd to occur in $7 \%$ of cases, but this estimate may be on the low side as many patients with the disease have not been subjected to radiological examination.

A variety of lesions occur, the commonest being scoliosis. Little is known about the pathological basis for this lesion, but it has variously been attributed to periosteal or intraosseous neurofibromata, or compensatory to other deformities. Disorders of skeletal growth are another feature, manifesting themselves in increase in length or stunting of growth, increase in density or rarefaction of the affected bones. The third group of bony lesions includes pedunculated periosteal growths, intracortical cysts or cysts within the medullary cavity. These may lead to fracture and pseudoarthrosis. Some of these lesions have been proven to be due to neurofibromata in the affected sites, but many have been diagnosed by radiological examination only and have been presumed to be neurofibromatous. Jaffe (1945) refers to the relative infrequency with which skeletal lesions of neurofibromatosis are due to the actual presence of a neurofibroma on a bone or within its interior. It must be emphasized that without histological examination it is impossible to be certain what proportion of bony lesions are definitely neurofibromatous.

Parkes Weber (1930) attributes the other abnormalities of bone such as hyperplasia to excessive blood supply secondary to the periosteal neurofibromatosis. Vascular anomalies do occur in this disease and some of the tumours are almost angiomatous. In the present case a remarkable feature was the abnormally rich blood supply incorporated within the periosteal and intramedullary tumours and this may have been a factor in causing thickening of the cortex and bowing of the tibiae.

In addition to these relatively distinctive skeletal lesions, there is a further small group of patients with the generalized bony changes of osteomalacia and it has been suggested that these patients have an associated renal tubular defect with excessive excretion of phosphate (Swann, 1954).

Two cases of Paget's disease have also been described in association with neurofibromatosis, but Levene (1959), in recording one such case, assumes that there is no definite connexion between the two conditions.

It is evident, therefore, that a wide range of skeletal manifestations may occur, and apart from osteomalacia which is seldom observed, intramedullary neurofibromata such as occurred in this case are probably the most rarely encountered or at least histologically proven bone lesions of neurofibromatosis.

A variety of endocrine disturbances may also occur and indeed Thannhauser (1944) subdivides neurofibromatosis into cutaneous, nervous, visceral, osseous and endocrine syndromes.

Endocrine disturbances include precocious puberty, hypogonadism, myxoedema, Addison's disease, and acromegaly. Ford (1960) emphasizes that the type of acromegaly which occurs is almost always atypical, and is more likely to be due to local disease of bone than to an endocrine disorder. It was difficult to find a basis for the enlargement 
of the clitoris in the present case. All endocrine organs were normal on histological examination, as was the hypothalamus. Petsche and Radlinger (1954) report a case with ovarian aplasia and external masculine pseudohermaphroditism. It is of interest that Biggart (personal communication) also recalls a case of neurofibromatosis in a female child who had a neurofibroma of the coeliac plexus associated with enlargement of the clitoris which subsided on surgical removal of the tumour. This suggests that the basis for this and possibly other endocrinopathies may occasionally be primarily neurogenic.

From the clinical point of view this case was interesting not only for the presence of fractures in the newborn, but also for the irregularity of the heart, with ventricular ectopics and runs of atrial tachycardia. This was attributable to diffuse neurofibromatosis of the vagi. Intrathoracic neurofibromata are relatively infrequent in von Recklinghausen's disease (Maksim, Henthorne and Allebach, 1939) and involvement of the vagus is very rare (Tuttle, Sanai and Harms, 1956). Gerbode and Marguiles (1953) were able to find only two reports of intrathoracic nerve sheath tumours which arose from the vagus.

Although a terminal septicaemia could not be excluded as the immediate cause of death in this patient, no doubt the cardiac dysfunction was a contributory factor.

\section{Summary}

A case of neurofibromatosis is described in an infant aged 4 weeks, presenting with skin pigmentation, pathological fractures, enlargement of the clitoris and cardiac irregularity. Extensive neurofibromatosis of peripheral nerves was found, including the vagi, together with a neurofibroma of the coeliac plexus. The fractures were related to intramedullary neurofibromata.

\section{REFERENCES}

Brooks, B. and Lehman, E. P. (1924). The bone changes in Recklinghausen's neurofibromatosis. Surg. Gynec. Obstet., 38, 587.

Ford, F. R. (1960). Diseases of the Nervous System in Infancy Childhood, and Adolescence, 4th ed., chap. 7, p. 1056. Blackwel Scientific Publications, Oxford.

Gerbode, F. and Marguiles, G. S. (1953). Neurofibromatosis with intrathoracic neurofibromas of vagus nerve. J. thorac. Surg., intrathorac 429.

Holt, J. F. and Wright, E. M. (1948). The radiologic features of neurofibromatosis. Radiology, 51, 647.

Jaffe, H. L. (1945). Fibrous dysplasia of bone. J. Mt Sinai Hosp., 12,364 .

Levene, L. J. (1959). Bone changes in neurofibromatosis. Arch. intern. Med., 103, 570.

Maksim, G., Henthorne, J. C. and Allebach, H. K. (1939). Neurofibromatosis with malignant thoracic tumor and metastasis in a child. Amer. J. Dis. Child., 57, 381.

Parkes Weber, F. (1930). Periosteal neurofibromatosis with a short consideration of the whole subject of neurofibromatosis. Quart. J. Med., 23, 151 .

Petsche, H. and Radlinger, C. (1954). Recklinghausen's disease with ovarian aplasia and external masculine pseudohermaphroditism (in German). Wien. Z. Nervenheilk., 10, 252.

Swann, G. F. (1954). Pathogenesis of bone lesions in neurofibromatosis. Brit. J. Radiol., 27, 623.

Thannhauser, S. J. (1944). Neurofibromatosis (von Recklinghausen) and osteitis fibrosa cystica localisata et disseminata (von Recklinghausen). Medicine (Baltimore), 23, 105.

Tuttle, W. M., Sanai, V. and Harms, H. P. (1956). Intrathoracic neurofibroma of the vagus nerve. A case report. $J$. thorac. Surg., 31, 632 . 